\title{
Assessing the Mental Health And Quality Of Life Of Transgenders: The Role Of Perceived Discrimination And Harassment
}

\author{
Manoj Kumar Pandey ${ }^{1}$ \\ ${ }^{1}$ Assistant Professor, Department of Applied Psychology, Veer Bahadur Singh Purvanchal University, \\ Jaunpur, Uttar Pradesh.
}

Corresponding author: Dr. Manoj Pandey

Email - dr.manojkumarpandey@yahoo.com

\begin{abstract}
Background: The social response towards transgenders in India is very discriminatory and prejudiced in general. They are experiencing discrimination in all domains of their personal and social life. They are even deprived of in their own families. Discrimination is believed to be associated with worse quality of life. The aim of this study was to explore the relationship between perceived discrimination and harassment with mental health and further quality of life in transgenders population.

Methods: The sample consists 60 transgenders (30 'Gurus' or Leaders and 30 are the 'Chellas' or Student)) belongs to Varanasi (U.P.) and Chhapra (Bihar). A non-random purposive sampling including the snowball technique was used to collect the data. The age range of the respondents are 18 to 55 years. A questionnaire consists of self-developed scale of mental health, quality of life, discrimination and harassment were administered. A consent form was filled from participants before the administration of the questionnaire.

Results: The results show that (a) 'Guru' (Leaders) were perceived more discrimination and less harassment in comparison to their 'Chellas' (Students). Further, it was also found that (b) 'Guru' (Leaders) have perceived poor mental health (more negative affect, anxiety, depression and stress) and quality of life (less life satisfaction, and but more social acceptance) in comparison to their 'Chellas' (Students). (c) Perceived discrimination and harassment were negatively related to mental health status and quality of life. (d) Perceived discrimination was accounted for maximum variation in mental health $(61.80 \%)$ while, component wise, perceived discrimination was accounted for maximum variation in anxiety (75.20\%) and depression $(68.50 \%)$ whereas, perceived harassment was accounted for maximum variation in negative affect or feelings $(67.20 \%)$ and stress $(70.30 \%)$. On the other hand, perceived discrimination was accounted for maximum variation in predicting quality of life $(63.70 \%)$. Component wise, perceived discrimination was accounted for maximum variation in life satisfaction $(84.20 \%)$ and socio-economic status $(57.50 \%)$ whereas, perceived harassment was accounted for maximum variation in social acceptance (55.30 \%) and (e) Mental health partially mediated in the relationship between perceived discrimination and harassment and quality of life. Results were discussed in light of previous researches and theories of this field.

Conclusion: Since, transgenders are regarded as the most disgraceful creature in this world. They are denied due to their status. The contribution of the study is important for understanding the pain and psychology of transgenders and aware others to include them in the mainstream society.
\end{abstract}

Keywords: Discrimination; Harassment, Mental Health, Quality of Life, Transgenders Individuals.

(Paper received - 23 ${ }^{\text {rd }}$ March 2018, Peer review completed $-25^{\text {th }}$ May 2018)

(Accepted - 28 ${ }^{\text {th }}$ May 2018) 


\section{INTRODUCTION}

A growing body of evidence suggests that experiences with discrimination have implications for mental health and that these associations may vary by social status [1]. Perceived discrimination is consistently, positively associated with impaired mental health across a vast array of cross-sectional and longitudinal data and has been linked to multiple mental health outcomes, including depressive symptoms, psychological distress, anxiety, and psychiatric disorders [2-4].

Transgenders people are facing discrimination, harassment and violence throughout society, from their family growing up, in school, at work, by homeless shelters, by doctors, in emergency rooms, before judges, by landlords, and even police officers [5]. Every day, transgenders and gender non-conforming people bear the brunt of social and economic marginalization due to discrimination based on their gender identity or expression. However, little is known about variation in the association between perceived discrimination and mental health across social status groups such as Transgenders people- a socially marginalized and deprived group.

The problems being faced by the Transgenders community have been brought to the notice of the Government in the recent past. In this regard, a meeting was organized by the Ministry of Social Justice \& Empowerment on 23rd August, 2013 to discuss the issues relating to Transgenders community such as social stigma, discrimination, lack of education, public health care, employment opportunities, issue of various government documents, etc.

The social response towards transgenders in India is seen very discriminatory and prejudiced in general. This study was an attempt to explore the relationship between perceived discrimination and harassment with mental health and quality of life of transgenders population.

\section{Transgenders}

Today, the term transgenders or in Indian notion 'Hijras' have a recorded history of more than 4,000 years. In India, the total population of transgenders is around $4.88 \mathrm{Lakh}$ as per 2011 census but the majority of them are invisible in mainstream society.

Transgenders is the state of one's gender identity or gender expression which does not match with ones assigned sex [6] and globally considered physically and psychologically ambivalent and because of ambivalence characteristics. They can encompass multiple labels or titles of people who do not fit the binary definitions of male or female. Some titles include transvestite, transsexual, cross-dresser, gender queer, nongendered, and drag king/queen.

Transgenders are quite often made to live on the fringe of the society and are referred with derogatory labels like 'hijras' [7-8]. The societal outlook, as well as acceptance of transgenders has been quite different in India than the western cultures. Ancient myths bestow them with special powers to bring luck and fertility. Yet, despite this supposedly sanctioned place in Indian culture, they are subjected to many social adversities. They often face discrimination in education, housing, health, employment and official bureaucratic dealings [9-10]. They are often required to tend to jobs below their intellectual capacity. Many generate income from petty extortion, performing at ceremonies, through begging and sex work [11].

Violence against transgenders, especially towards sex workers, is common and occurs in a variety of settings [12-13]. Many transgenders have experienced abuse during childhood, and the rates of sexual abuse has been reported to be higher in transgenders than those with other gender orientations [14]. These adverse life circumstances are likely to have adverse psychological impact on transgenders. Moreover, access to health care services are reported to be more adversarial towards transgenders, which may result in their health concerns not being addressed fairly [15].

\section{Perceived Discrimination, Harassment and Mental Health}

The World Health Organization (2004) defines the concept of mental health status as, "a state of well-being in which the individual realizes his or her own abilities, can cope with the normal stresses of life, can work productively and fruitfully, and is able to make a contribution to his or her community." [16]

Sen Gupta and gave six indices of mentally healthy person namely, adjustment, emotional stability, intelligence, autonomy, security-insecurity, activity-level [17]. Mental health thus involves a continuous 
process of adjustment through optimum use of one's potentialities rather than a static condition. Mental health of police employees may be influenced by a number of work environmental factors such as sexual harassment, leadership style, stressful condition of the work, peer group support, family influence, and accessibility of coping mechanism.

Discrimination in general is classically defined as a phenomenon that involves 'deny(ing) to individual or groups of people equality of treatment which they may wish' [18]. Recognized as a worldwide experience, discrimination in terms of gender and sexuality is no exception [19]. India is not known for being a LGBTIQ - friendly place at a macro level, that is, in social arenas. There is little protection under the recent provision made by the Supreme Court of India discrimination on the basis of sexual orientation and gender identity. Though the 'Hijras' are tolerated by the Indian society. They are not accepted and are discriminated against in various settings, first because of their transgenders status-their cross-dressing or feminine appearancewhich is often ridiculed and second, because of their presumed occupation, sex work [20].

Previous studies consistently reported the link between perceived discrimination and mental health, namely more individual experiences of discrimination are associated with poor mental health and mental diseases [21-22]. Discrimination was also reported to be associated with many physical health measures, including high blood pressure [23-24], respiratory problems [25], self-rated health [26-27] and chronic health conditions [28-29]. Mental health may be affected by perceived discrimination more than physical health [30].

Grant and others released a comprehensive study on discrimination with 6,450 transgenders and gender non-conforming study participants for the National Centre for Transgenders Equality and National Gay and Lesbian Task Force [31]. Discrimination was found to be pervasive throughout the entire sample. Respondents lived in extreme poverty. A staggering $41 \%$ of respondents reported attempting suicide compared to $1.6 \%$ of the general population, with rates rising for those who lost a job due to bias (55\%), were harassed /bullied in school (51\%), had low household income, or were the victims of physical assault $(61 \%)$ or sexual assault (64\%). Ninety percent of transgenders individuals have encountered some form of harassment or mistreatment on the job. Respondents reported various forms of direct housing discrimination. Almost half of the respondents (46\%) reported being uncomfortable seeking police assistance. Nineteen percent of the sample reported being refused medical care due to their transgenders or gender non-conforming status, with even higher numbers among people of color in the survey.

Mustanski, Garofalo and Emerson sought to address some of the gaps in past research by conducting structured diagnostic interviews in a community-sample of 246 LGBT youth [32]. Participants in the study were very diverse in terms of ethnicity and were between the ages of 16-20 years old, with an average age of 18. It was found that nearly $10 \%$ of study participants met criteria for post-traumatic stress disorder (PTSD) and about $15 \%$ met criteria for major depression. A third of the participants had made a suicide attempt at some point in their life.

Transgenders individuals are particularly vulnerable to mental health concerns and psychological distress [32]. Regarding specific psychological distress, research has shown that transgenders individuals report higher levels of both anxiety and depression than the population as a whole. Depression has been reported to affect $16.6 \%$ of the total population, and combined anxiety disorders affect $28.8 \%$ of the United States population [33].

Within the literature, rates of depression for transgenders individuals range from $48 \%$ to $62 \%$ [31-33]. Anxiety and overall distress rates for transgenders individuals range from $26 \%$ to $38 \%$ [30,34].

Although the rates of depression, anxiety, and overall distress indicate above-average rates for the transgenders population, there are only several studies that examine potential explanations for these findings. Nuttbrock and others report that there is a significant positive relationship between gender-related abuse and depression in transgenders women. The authors note that social stressors and/or ostracism from peers can explain a large amount of the depression that is reported by the individuals in their study [35].

Budge and others in their qualitative study indicate that distress varies on the basis of several factors, including the individual's transition process, coping mechanisms used, and level of social support. Although both of these studies provide insight into possible explanations for contributing factors to transgenders individuals' distress, there continues to be a lack of generalizable information regarding the actual process through which individuals cope with and experience depression and anxiety [36]. 
Social anxiety is possibly the most prevalent disorder found among transgenders people, with studies in 2005 and 2010 showing that $55 \%$ of transgenders people experience high levels of anxiety, compared to only $6.8 \%$ of the cisgender (non-transgenders) population [37].

Transgender people may find themselves living in constant fear of verbal harassment or physical violence. While a healthy mind can deal with this kind of pressure for short periods, over time a perpetual sense of danger may develop into debilitating forms of anxiety and/or depression. Tragically, this also leads to an increased rate of suicide attempts in the transgender community (as compared with cisgender individuals). Grossman and D'Augelli [38] studied the risk factor of suicide among transgenders youth. Nearly half of the sample reported having seriously thought about taking their lives and one quarter reported suicide attempts. Factors significantly related to having made a suicide attempt included suicidal ideation related to transgenders identity; experiences of past parental verbal and physical abuse; and lower body esteem, especially weight satisfaction and thoughts of how others evaluate the youths' bodies.

Pascoe and Smart Richman [39] found that perceived discrimination has negative physical and mental health outcomes, and that it also heightens perceived stress. Harris and others associated discrimination with poor or fair self-rated health, lower physical functioning, lower mental health, smoking, and cardiovascular disease [40].

\section{Perceived Discrimination, Harassment and Quality of Life}

Quality of Life (QoL) is a broader concept than personal health status. Lindström defines QoL as the total essence of existence of an individual, a group, or a society, as measured objectively and perceived subjectively [40].

Sex discrimination harassment can also occur, in which unwelcome sexual advances or non-sexual offensive comments are made about a person's sex (Equal Employment Opportunity Commission).

Discrimination has found deleterious influences on health and quality of life in previous researches. Discrimination is believed to be associated with worse quality of life (QoL) in study done by Başar and others [41]. In India, a study done by Aneesh M.S. (2017) has reported that 13\% of transgenders of Kerala positively rated that they have good quality of life. The overall perception of their quality of life shows that $16 \%$ rated very good quality of life, $30 \%$ rated as neither poor nor good, $35 \%$ are negatively rated that they have very poor quality of life and remaining $6 \%$ have poor quality of life. It is understood that majority of the respondents believes that they possess poor quality of life [42].

Further, in India there has not been much academic interest in studying, understanding, and debating the transgenders issues. Much of the studies concern were in field of legal perspectives, discrimination in uses of health care systems, understanding their social and economic problems,

This study was an attempt to understand the problems faced by transgenders in terms of psychological consequences of perceived discrimination and harassment in their personal and professional domain of life. How these perceptions of discriminations and harassment are affecting their mental health and further quality of life.

On the basis of aforementioned literatures in the field of transgenders researches around the world and India, researcher has proposed following model explaining the relationships between the variables of the research.

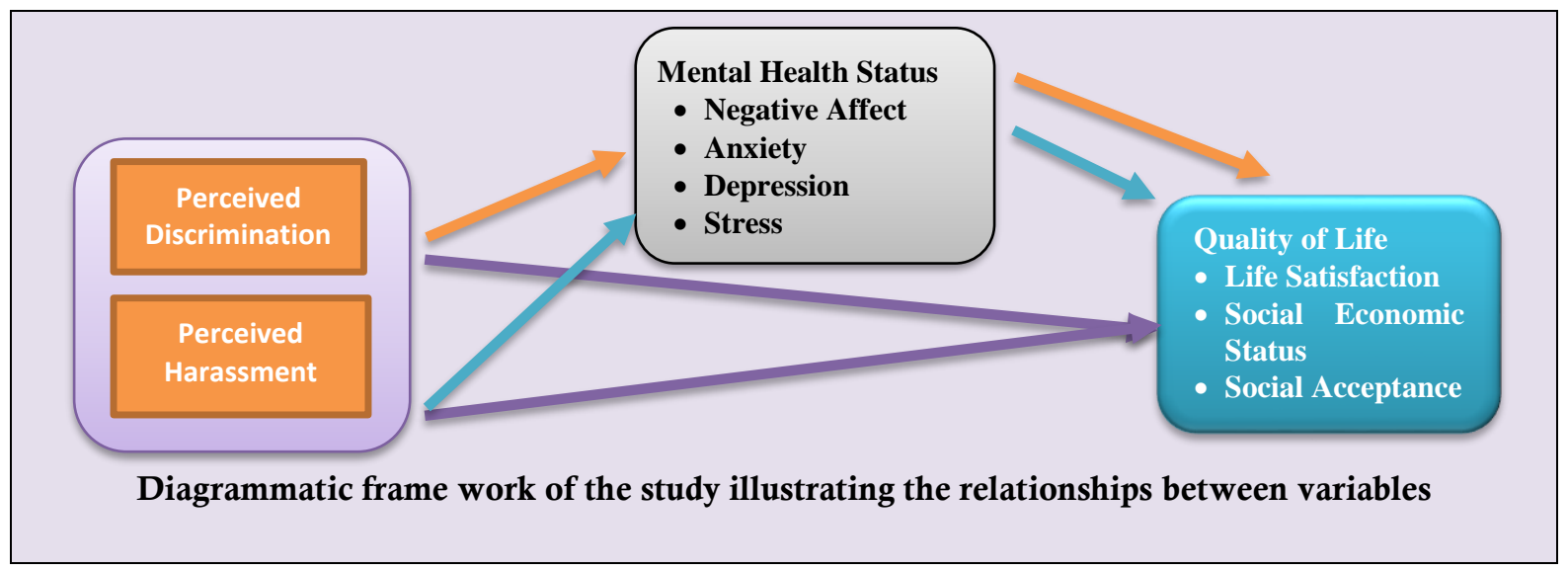


The following research hypothesis were formulated to establishing the link between the objectives of the research.

- $\mathrm{H}_{1}$ : (a) 'Guru' (Leaders) will have more perceived discrimination and less harassment in comparison to their 'Chellas' (Students). (b) 'Guru' (Leaders) will have poor mental health and quality of life in comparison to their 'Chellas' (Students).

- $\mathrm{H}_{2}$ : Perceived discrimination will negatively affect the mental health \& quality of life of transgenders people in terms of more negative affect, low level of life satisfaction, more anxiety and depression.

- $\mathrm{H}_{3}$ : Perceived harassment in social and profession life will negatively affect the mental health \& quality of life of transgenders people in terms of more negative affect, low level of life satisfaction, more anxiety and depression.

- $\mathrm{H}_{4}$ : Mental health status will mediate the relationship between perceived discrimination and quality of life (life satisfaction, socio-economic status, acceptance) of transgenders.

- $\mathrm{H}_{5}$ : Mental health status will mediate the relationship between perceived harassment and quality of life (life satisfaction, socio-economic status, acceptance) of transgenders.

\section{METHODOLOGY}

\section{Participants}

The sample consists 60 transgenders (30 'Gurus' or leaders and 30 are the 'Chellas' or Student)) belongs to Varanasi (U.P.) and Chhapra (Bihar). A non-random purposive sampling including the snowball technique was used to collect the data. The age range of the respondents are 18 to 55 years with a mean scores of 38.3 years.

A questionnaire consists of self-developed measures of mental health status, quality of life, perceived discrimination and harassment were administered. A consent form was filled from participants before the administration of the questionnaire.

\section{Criteria for selecting the sample}

- Only transgenders having by birth and castrated were selected for the study confirmed by 'Guru' (Leader)

- Age of the 'Chellas' (students) are restricted between 18 to 35 years and for Gurus 40 to 55+ Years.

- Their economic sources are: private jobs in company, begging money during travelling in trains and crossing.

- They were taken from urban background i.e. city location.

- For members of the community, at least 6 months of membership in the group was compulsory for 'Chellas' (students).

\section{Study Measures}

Perceived discrimination: In this study, perceived discrimination was operationalized in terms of transgenders's experiences of day-to-day discriminations at school (discouraged from continuing education, denied a scholarship), work (not hired or promoted, fired), receiving financial and other services (denied a bank loan, prevented from renting or buying a home, given inferior services), and experiences with social hostility (forced out of a neighborhood, hassled by the police). The scale consists of 9 items indicating their experience of discrimination on five point rating scale (where ' 0 ' indicates no discrimination and ' 4 ' indicates maximum level of perceived discrimination).

Respondents were asked to indicate how frequently they experienced each of 9 types of discrimination on a day-to-day basis. For each, respondents chose between 0 to 4 descriptors ("never," "rarely," "sometimes," "often" and "always"). Because we were interested in the prevalence of relatively common experiences with discrimination. The Cronbach's Alpha coefficient of this self-developed scale is 0.728 on 9 items. 
Perceived Harassment: In this study, perceived harassment was operationalized in terms of transgenders's experiences of being harassed or mistreatment by police, people, colleagues etc. while begging in trains and at crossing or workplace. The scale consists of 9 items indicating their experience of discrimination on five point rating scale (where ' 0 ' indicates no discrimination and ' 4 ' indicates maximum level of perceived discrimination). Respondents were asked to indicate how frequently they experienced each of 9 types of discrimination on a day-to-day basis. For each, respondents chose between 0 to 4 descriptors ("never," "rarely," "sometimes," "often" and "always"). Because we were also interested in the prevalence of relatively common experiences with harassment. The Cronbach's Alpha coefficient of this self-developed scale is 0.681 on 3 items. Most of them were reported high rate of physical harassment by police (62\%) followed by public ( $45 \%)$ and colleagues $(23 \%)$.

Mental Health Status: Mental health status was operationalized in terms of positive and negative affect, anxiety, depression, and stress. The index consists of 30 items was the combinations of four measures which was adopted by researcher for this study. Hindi adaptation of PANAS scale (Pandey, Manoj Kumar), and self-developed items for anxiety, depression and stress were used for assessing mental health status of transgenders. Items were rated on a five point rating scale where respondents had to choose between 0 to 4 descriptors ("never," "rarely," "sometimes," "often" and "always"). The Cronbach's Alpha coefficient of his index is 0.833 on 30 items.

Quality of Life (QoL): Quality of life was operationalized in terms of life satisfaction, socio-economic status, and social acceptance as perceived by transgenders. Hindi adaptation of life satisfaction scale (Diener, E. et.al. 1985) and self-developed items were used for assessing perceived socio-economic-status and social acceptance by transgenders [42]. Items were rated on a five point rating scale where respondents has chosen between 1 to 5 descriptors ("very less", "less", "neutral", "much" and "very much"). The Cronbach's Alpha coefficient of this scale is 0.774 on 24 items.

\section{Data Collection}

The first ten minutes of initial talk involved reading and discussing the informed consent form. The form contains information about the purpose of the study, the participant's rights, the risks and benefits of the study and contact information for the researcher. The consent form also asks for the participant to give consent to be re-contacted so that researcher can get feedback during the analysis process. This study is a part of previously done project work [43] which included semi-structured interviews with participants and questionnaires. As a part of that project, participants were asked to filled the form or give their responses of booklet of questionnaire (those who are unable to read the form). Before starting the data collection, a written informed consent was obtained from the participants and confidentiality of the information were assured. They were also assured that the information collected was used only for the purpose of the research.

\section{STATISTICAL ANALYSIS}

The data obtained from this study was analyzed for testing the hypotheses and understand the patterns of relationships among the variables understudy. For which ANOVA, inter-correlations among variables and stepwise regression analysis were used with the help of IBM SPSS 23 version

\section{RESULTS AND DISCUSSION}

This study was an attempt to understand the problems faced by transgenders in terms of psychological consequences of discrimination and harassment in their personal and professional domain of life. In other word, how these perceived discriminations and harassment are affecting their mental health and quality of life.

\section{Differences in Perception of Discrimination and Harassment}

It was hypothesized that (a) 'Guru' (Leaders) will have more perceived discrimination and less harassment in comparison to their 'Chellas' (Students). (b) 'Guru' (Leaders) will have poor mental health and quality of life in comparison to their 'Chellas' (Students). 
Table 1

One-way ANOVA for finding the significance of the mean difference between 'Guru' and 'Chellas' on perception of discrimination, harassment, mental health and quality of life

\begin{tabular}{|c|c|c|c|c|c|c|c|c|c|c|c|c|c|c|c|c|c|c|c|c|c|c|}
\hline \multicolumn{3}{|c|}{ Discrimination } & \multicolumn{2}{|c|}{ Harassment } & \multicolumn{10}{|c|}{ Mental Health Status } & \multicolumn{8}{|c|}{ Quality of Life Index } \\
\hline & & & & & \multicolumn{2}{|c|}{$\begin{array}{l}\text { Mental } \\
\text { Health }\end{array}$} & \multicolumn{2}{|c|}{$\begin{array}{c}\text { Negative } \\
\text { Affect }\end{array}$} & \multicolumn{2}{|c|}{ Anxiety } & \multicolumn{2}{|c|}{ Depression } & \multicolumn{2}{|c|}{ Stress } & \multicolumn{2}{|c|}{$\begin{array}{c}\text { Quality of } \\
\text { Life }\end{array}$} & \multicolumn{2}{|c|}{ ife Satisfaction } & \multicolumn{2}{|c|}{$\begin{array}{l}\text { Socio- } \\
\text { Econ }\end{array}$} & \multicolumn{2}{|c|}{$\begin{array}{c}\text { Social } \\
\text { Acceptance }\end{array}$} \\
\hline & $\mathrm{G}$ & $\mathrm{C}$ & $G$ & $\mathrm{C}$ & $G$ & $\mathrm{C}$ & $\mathrm{G}$ & $\mathrm{C}$ & $\mathrm{G}$ & $\mathrm{C}$ & $\mathrm{G}$ & $\mathrm{C}$ & $\mathrm{G}$ & $\mathrm{C}$ & $\mathrm{G}$ & $\mathrm{C}$ & $\mathrm{G}$ & $\mathrm{C}$ & $\mathrm{G}$ & $\mathrm{C}$ & G & $\mathrm{C}$ \\
\hline $\mathrm{N}$ & 30 & 30 & 30 & 30 & 30 & 30 & 30 & 30 & 30 & 30 & 30 & 30 & 30 & 30 & 30 & 30 & 30 & 30 & 30 & 30 & 30 & 30 \\
\hline $\bar{M}$ & 3.95 & 2.65 & 2.86 & 3.78 & 4.23 & 3.21 & 3.68 & 4.43 & 4.54 & 3.65 & 3.43 & 2.14 & 3.89 & 2.32 & 2.25 & 4.32 & 2.54 & 3.86 & 3.32 & 3.43 & 3.98 & 2.21 \\
\hline $\begin{array}{l}\mathrm{S} \\
\mathrm{D}\end{array}$ & .674 & .497 & 4.12 & .567 & .674 & .564 & .543 & .675 & .345 & .653 & .653 & .543 & .432 & .552 & .412 & .45 & .456 & .553 & .432 & .342 & .342 & .435 \\
\hline $\mathrm{F}$ & \multicolumn{2}{|c|}{$4.432^{* *}$} & \multicolumn{2}{|c|}{$3.432 * *$} & \multicolumn{2}{|c|}{$5.321 * *$} & \multicolumn{2}{|c|}{$3.126^{*}$} & \multicolumn{2}{|c|}{$3.198^{*}$} & \multicolumn{2}{|c|}{$4.231^{* *}$} & \multicolumn{2}{|c|}{$3.982^{* *}$} & \multicolumn{2}{|c|}{$5.124^{* *}$} & \multicolumn{2}{|c|}{$3.894^{* *}$} & 1.98 & & \multicolumn{2}{|c|}{$4.345^{* *}$} \\
\hline
\end{tabular}

${ }^{* * *} \mathrm{p}<.001$ level, ${ }^{* *} \mathrm{p}<.01$ level, ${ }^{*} \mathrm{p}<.05$ level (2-tailed test)

Higher scores on perceived discrimination \& harassment indicates higher level discrimination and harassment.

Higher scores on Mental Health Status Index indicates higher level negative affects, anxiety, depression, and stress

Higher scores on quality of life index indicates high level of quality of life.

The one-way ANOVA was computed for examining the significance of the differences of the mean scores (a) 'Guru' (Leaders) and 'Chellas' (Students) on perception discrimination and less harassment, mental health and quality of life in comparison to their 'Chellas' (Students). Results revealed that (a) 'Guru' (Leaders) were perceived more discrimination and less harassment in comparison to their 'Chellas' (Students). Further, it was also found that (b) 'Guru' (Leaders) have perceived poor mental health (more negative affect, anxiety, depression and stress) and quality of life (less life satisfaction, and but more social acceptance) in comparison to their 'Chellas' (Students). There is no significant difference was found on socio-economic status of both groups. Thus, the results support the hypothesis $\mathrm{H}_{1}$.

'Guru' (Leaders) were reported poor mental health related issues and quality of life because of they are now dependent on their 'Chellas' in terms of economic support, care, love and affection. Although, they are living in a group of same people but sometimes they are ignored by their 'Chellas' like an old tiger. They are just spending their time to seek a peaceful end of life.

\section{Relationships between Perceived Discrimination and Harassment with Mental Health Status and Quality of Life in Transgenders}

It was hypothesized that (a) perceived discrimination will negatively affect the mental health \& quality of life of transgenders people. (b) Perceived harassment in social and profession life will negatively affect the mental health \& quality of life of transgenders people.

Table 2

Coefficient of correlation between perceived discrimination and harassment with mental health status and quality of life among transgenders.

\begin{tabular}{|c|c|c|c|c|c|c|c|}
\hline & \multicolumn{3}{|c|}{ Mental Health Status Index } & \multicolumn{3}{c|}{ Quality of Life Index (QoL) } \\
\cline { 2 - 7 } & $\begin{array}{c}\text { Positive } \\
\text { Affect }\end{array}$ & $\begin{array}{c}\text { Anxiet } \\
\mathrm{y}\end{array}$ & $\begin{array}{c}\text { Depressio } \\
\mathrm{n}\end{array}$ & Stress & $\begin{array}{c}\text { Life } \\
\text { Satisfaction }\end{array}$ & $\begin{array}{c}\text { Socio-Economic } \\
\text { Status }\end{array}$ & $\begin{array}{c}\text { Social } \\
\text { Acceptance }\end{array}$ \\
\hline $\begin{array}{c}\text { Perceived } \\
\text { discrimination }\end{array}$ & $-0.621^{* *}$ & $0.430^{* *}$ & $0.451^{* *}$ & $0.474^{* *}$ & -0.144 & $-0.305^{* *}$ & $0.405^{* *}$ \\
\hline $\begin{array}{c}\text { Perceived } \\
\text { harassment }\end{array}$ & $-0.572^{* *}$ & $0.501^{* *}$ & $0.327^{* *}$ & $0.542^{* *}$ & $-0.220^{*}$ & $-0.317^{* *}$ & $0.242^{*}$ \\
\hline
\end{tabular}

Note: ${ }^{*} p<0.05$ level (2-tailed), ${ }^{* *} p<0.01$ level (2-tailed). 
Higher scores on perceived discrimination \& harassment indicates higher level discrimination and harassment. Higher scores on Mental Health Status Index indicates higher level negative affects, anxiety, depression, and stress. Higher scores on quality of life index indicates high level of quality of life.

On the basis of the results presented in Table- 2 we can say that (a) perceived discrimination is significantly negatively correlated with mental health and quality of life. (b) Perceived harassment was also found significant negatively correlated with mental health and quality of life among transgenders. The obtained results supports the true hypothesis $\mathrm{H}_{2} \& \mathrm{H}_{3}$.

Further on the basis of this result, it can be said that discriminations and harassments (physical and psychological) in social and professional life are found responsible for creating more negative affect or feelings, anxiety, depression and stress among transgenders. It can be also said that discriminations and harassments (physical and psychological) in social and professional life are accountable for poor quality of life in terms of less life satisfaction, low socio-economic-status (respect, economic crisis, love etc.), and less social acceptance (inclusion of main stream society, social participation etc.) among transgenders.

Previous studies consistently reported the link between perceived discrimination and mental health, namely more individual experiences of discrimination are associated with poor mental health and mental diseases $[2-3,20]$. Discrimination was also reported to be associated with many physical health measures, including high blood pressure [22-23], respiratory problems [24], self-rated health [25-26] and chronic health conditions [27-28]. Mental health may be affected by perceived discrimination more than physical health [29].

Transgender people may find themselves living in constant fear of verbal harassment or physical violence. Grossman and D'Augelli [40] studied the risk factor of suicide among transgenders youth [39, 48-50]. Factors significantly related to having made a suicide attempt included suicidal ideation related to transgenders identity; experiences of past parental verbal and physical abuse; and lower body esteem, especially weight satisfaction and thoughts of how others evaluate the youths' bodies.

Pascoe and Smart Richman found that perceived discrimination has negative physical and mental health outcomes, and that it also heightens perceived stress [39]. Discrimination has found harmful influences on health and quality of life in previous researches [40-44].

On the basis of bivariate correlation analysis, it is not sure that which one is the best predictors for the outcome variables or to know which one among discrimination and harassment is responsible for assessing poor mental health (negative affect or feelings, anxiety, depression and stress) and quality of life (life satisfaction, socio-economic-status and social acceptance) among transgenders, stepwise regression analysis was done for predicting the outcome variable more accurately and presented in Table No-3.

\section{Predicting mental health and quality of life along with their dimensions from perceived discrimination and harassment at social and professional life}

Higher scores on perceived discrimination \& harassment indicates higher level discrimination and harassment. Higher scores on Mental Health Status Index indicates higher level negative affects, anxiety, depression, and stress. Higher scores on quality of life index indicates high level of quality of life.

Stepwise regression analysis was done to find out the best predictors among perceived discrimination and harassment to determine the maximum contribution in assessing the negative impact on mental health status and quality of life of transgenders.

The predictor variables, which were found to be most significantly predicting the criterion variable are presenting here. (a) Perceived discrimination was accounted for maximum variation in mental health $(61.80 \%)$. Component wise perceived discrimination was accounted for maximum variation in anxiety $(75.20 \%)$ and depression $(68.50 \%)$ while perceived harassment was accounted for maximum variation in negative affect or feelings (67.20 \%) and stress (70.30\%).

On the other hand, (b) Perceived discrimination was accounted for maximum variation in predicting quality of life $(63.70 \%)$. Component wise perceived discrimination was accounted for maximum variation in life satisfaction $(84.20 \%)$ and socio-economic status $(57.50 \%)$ while perceived harassment was accounted for maximum variation in social acceptance (55.30 \%). 
Table No. 3

Showing the stepwise regression analysis to determine the best predictors of (a) mental health (negative affect or feelings, anxiety, depression and stress) and (b) quality of life (life satisfaction, socio-economicstatus and social acceptance) from perceived discrimination and harassment.

\begin{tabular}{|l|l|c|c|c|c|c|c|}
\hline $\begin{array}{l}\text { Predictor } \\
\text { Variable }\end{array}$ & $\begin{array}{l}\text { Dependent } \\
\text { Variables }\end{array}$ & $\mathrm{R}$ & $\begin{array}{c}\text { Adjusted } \\
\mathrm{R} \\
\text { Square }\end{array}$ & $\begin{array}{c}\mathrm{R} \\
\text { Square } \\
\text { Change }\end{array}$ & $\begin{array}{c}\text { Standardized } \\
\text { Coefficients } \\
(\beta)\end{array}$ & t-value & Sig. \\
\hline \multicolumn{7}{|c|}{ Mental Health Status and Components } \\
\hline Discrimination & Mental Health & 0.618 & 0.617 & 0.618 & 0.856 & $11.150^{* * *}$ & 0.000 \\
\hline Harassment & Negative Affect & 0.673 & 0.672 & 0.673 & 0.761 & $9.216^{* * *}$ & 0.000 \\
\hline Discrimination & Anxiety & 0.752 & 0.751 & 0.752 & 0.733 & $8.783^{* * *}$ & 0.000 \\
\hline Discrimination & Depression & 0.685 & 0.684 & 0.685 & 0.794 & $6.743^{* * *}$ & 0.000 \\
\hline Harassment & Stress & 0.703 & 0.702 & 0.703 & 0.643 & $8.956^{* * *}$ & 0.000 \\
\hline \multicolumn{8}{|c|}{ Quality of Life and Components } \\
\hline Discrimination & Quality of Life & 0.637 & 0.636 & 0.637 & 0.672 & $7.0124^{* * *}$ & 0.000 \\
\hline Discrimination & Life Satisfaction & 0.842 & 0.841 & 0.842 & 0.690 & $7.674^{* *}$ & 0.008 \\
\hline Discrimination & $\begin{array}{l}\text { Socio-Economic } \\
\text { Status }\end{array}$ & 0.575 & 0.574 & 0.575 & 0.581 & $6.893^{* *}$ & 0.006 \\
\hline Harassment & $\begin{array}{l}\text { Social } \\
\text { Acceptance }\end{array}$ & 0.553 & 0.552 & 0.553 & 0.632 & $6.121^{* *}$ & 0.005 \\
\hline
\end{tabular}

In sort, perceived discrimination was found more accountable or predicting maximum in assessing the impact on mental health and quality of life. Since, transgender people are confronted at every turn with discrimination - in school, at work, on the streets, in the doctor's office, in the line for public assistance, in the restroom, in the boardroom, and many more places. Even in their own homes. It is exhausting, it is frightening, and it is, for far too many people, almost continuous [45-46].

Mediating role of mental health in the relationship between perceived discrimination and harassment and quality of life of transgenders

It was hypothesized that mental health status will mediate the relationship between (a) perceived discrimination and quality of life (life satisfaction, socio-economic status, acceptance) of transgenders \& (b) perceived harassment and quality of life (life satisfaction, socio-economic status, acceptance) of transgenders.

Mediation analysis was carried out to assess the mediating role of mental health on the relationship between perceived discrimination and harassment and quality of life. To test the mediation, the procedure suggested by Baron and Kenny was adopted; the steps have been stated below:

- The independent and dependent variable must be significantly related

- The independent and mediating variable must be significantly related

- The mediator and dependent variable must be significantly related and

- The independent variable must have no effect on the dependent variable when the mediator is held constant (full mediation) or should become significantly smaller (partial mediation).

The hierarchical linear regression analyses for exploring the mediating role of mental health are demonstrated in Table 4.

Higher scores on perceived discrimination \& harassment indicates higher level discrimination and harassment. Higher scores on Mental Health Status Index indicates higher level negative affects, anxiety, depression, and stress. Higher scores on quality of life index indicates high level of quality of life. 
Table 4

\begin{tabular}{|c|c|c|c|c|c|c|c|c|c|c|}
\hline Mediation Steps & \multicolumn{2}{|c|}{$\begin{array}{c}\text { Non- } \\
\text { Standardized } \\
\text { Coefficients }(\beta)\end{array}$} & \multicolumn{2}{|c|}{ Std. Error } & \multicolumn{2}{|c|}{$\begin{array}{c}\text { Standardized } \\
\text { Coefficients }(\beta)\end{array}$} & \multicolumn{2}{|c|}{$\mathrm{t}$-value } & \multicolumn{2}{|c|}{ Sig. } \\
\hline 1 & 0.681 & 0.781 & 0.060 & 0.069 & 0.625 & 0.712 & 10.483 & 13.423 & .000 & .000 \\
\hline 2 & 0.587 & 0.653 & 0.078 & 0.079 & 0.476 & 0.567 & 6.825 & 8.655 & .000 & .000 \\
\hline 3 & 0.402 & 0.589 & 0.048 & 0.053 & 0.484 & 0.653 & 7.624 & 7.224 & .000 & .000 \\
\hline \multicolumn{11}{|c|}{ Sobel Test Results } \\
\hline Mediation Type & \multicolumn{2}{|c|}{ Z Score } & \multicolumn{2}{|c|}{ Direct Effect } & \multicolumn{2}{|c|}{ Indirect Effect } & \multicolumn{2}{|c|}{ Total Effect } & \multicolumn{2}{|c|}{ Sig. } \\
\hline \begin{tabular}{l|l|} 
Partial & Partial
\end{tabular} & 3.64 & 3.79 & 0.542 & .654 & 0.133 & .234 & 0.675 & .888 & .000 & .000 \\
\hline
\end{tabular}

Results indicate perceived discrimination and harassment was negatively and significantly related to the quality of life $(b=0.625, p<0.001 ; b=0.712, p<0.001)$, perceived discrimination was negatively and significantly related to the mental health $(b=0.476, p<0.001 ; b=0.567, p<0.001)$ and mental health was negatively and significantly related to the quality of life $(b=0.253, p<0.001 ; b=0.312, p<0.001)$. Thus, the steps one, two, three of the mediation analysis were supported. Furthermore, results show that after mental health was taken into account in first condition, the beta weight for perceived discrimination dropped from the initial level of 0.625 to $0.511 \& .712$ to .653 , although still significant $(b=0.487, p<0.001 ; b=$ $0.653, \mathrm{p}<0.001)$. Thus, mental health satisfied the requirements of a partial mediator in the relationship between perceived discrimination and harassment and quality of life. To further assess the significance of the mediation, a Sobel test $(\mathrm{z}=3.64 \mathrm{p}<0.001 ; \mathrm{z}=3.79 \mathrm{p}<0.001)$ was obtained. Thus, our hypothesis $\mathrm{H}_{4}$ $\& \mathrm{H}_{5}$ were partially supported.

\section{Implication of the Research and Future Direction}

Living with the identity of transgender is very difficult in India as they are facing discrimination in every step in their life starting from their own family to the society. They are suffering from their birth to till death and after death also. Multiple problems are faced by transgenders, which necessitate a variety of solutions and actions. While some actions require immediate implementation such as introducing transgender's specific social welfare schemes, some actions need to be taken on a long-term basis changing the negative attitude of the general public and increasing accurate knowledge about transgender's communities. The required changes need to be reflected in policies and laws; attitude of the government, general public and health care providers; and health care systems and practice. One of his own effort, researcher has tried to aware people, academician and government about the inclusion of these socially excluded group in to the mainstream society try to understand their pain of being transgender [44].

\section{CONCLUSION}

It is suggested that still we need to address their problems on a large scale. Although, government and law have made some provisions on paper, but still it need to be implemented on ground level. People need to understand that they are the part of our society not a person to be hate, discriminate, harass and treat them in a different way. They can contribute our society or even our nation like us.

\section{REFERENCES}

1. Lee H, Turney K. Investigating the relationship between perceived discrimination, social status, and mental health. Soc Ment Health 2012;2(1):1-20.

2. Paradies Y. A systematic review of empirical research on self-reported racism and health. Int J Epidemiol 2006;35(4):888-901.

3. Williams DR, Mohammed SA. Discrimination and racial disparities in health: evidence and needed research. J Behav Med 2009;32(1):20-47. 
4. Williams DR, Neighbors HW, Jackson JS. Racial/ethnic discrimination and health: findings from community studies. Am J Pub Health 2003;93(2):200-8.

5. Grant JM, Mottet L, Tanis JE, Harrison J, Herman J, Keisling M. Injustice at every turn: A report of the national transgender discrimination survey. National Center for Transgender Equality; 2011.

6. GLAAD Media Reference Guide. Transgender Issues, GLAAD. 2011.

7. Kalra G. Hijras: the unique transgender culture of India. Int J Culture Ment Health 2012;5(2):121-6.

8. Nanda S. The Hijras of India: J Homosexuality 1986;11:35-54.

9. Bradford J, Reisner SL, Honnold JA, Xavier J. Experiences of transgender-related discrimination and implications for health: results from the Virginia Transgender Health Initiative Study. Am J Pub Health 2013;103(10):1820-9.

10. Kosenko K, Rintamaki L, Raney S, Maness K. Transgender patient perceptions of stigma in health care contexts. Med Care 2013;51(9):819-22.

11. Abdullah MA, Basharat Z, Kamal B, Sattar NY, Hassan ZF, Jan AD, Shafqat A. Is social exclusion pushing the Pakistani Hijras (Transgenders) towards commercial sex work? A qualitative study. BMC Int Health Hum Rights 2012;12(1):32.

12. Moran LJ, Sharpe AN. Violence, identity and policing: The case of violence against transgender people. Crim Justice 2004;4(4):395-417.

13. Witten TM, Eyler AE. Hate crimes and violence against the transgendered. Peace Review 1999;11(3):461-8.

14. Friedman MS, Marshal MP, Guadamuz TE, Wei C, Wong CF, Saewyc EM, Stall R. A meta-analysis of disparities in childhood sexual abuse, parental physical abuse, and peer victimization among sexual minority and sexual nonminority individuals. Am J Pub Health 2011;101(8):1481-94.

15. Beattie TS, Bhattacharjee P, Suresh M, Isac S, Ramesh BM, Moses S. Personal, interpersonal and structural challenges to accessing HIV testing, treatment and care services among female sex workers, men who have sex with men and transgenders in Karnataka state, South India. J Epidemiol Commun Health 2012;66(Supp1 2):42-8.

16. Sen Gupta A. \& Singh AK. Mental Health Battery (MHB), Lucknow: Ankur Psychological Agency. 1983.

17. Allport G. The Nature of Prejudice. Basic Books, New York.1979.

18. Koken JA, Bimbi DS, Parsons JT. Experiences of familial acceptance-rejection among transwomen of color. J Fam Psychol 2009;23(6):853-70.

19. Chakrapani V, Babu P, Ebenezer T. Hijras in sex work face discrimination in the Indian health-care system. Res Sex Work 2004;7:12-4.

20. Borrell LN, Kiefe CI, Williams DR, Diez-Roux AV, Gordon-Larsen P. Self-reported health, perceived racial discrimination, and skin color in African Americans in the CARDIA study. Soc Sci Med 2006;63(6):1415-27.

21. Veling W, Selten JP, Susser E, Laan W, Mackenbach JP, Hoek HW. Discrimination and the incidence of psychotic disorders among ethnic minorities in The Netherlands. Int J Epidemiol 2007;36(4):761-8.

22. Krieger N, Sidney S. Racial discrimination and blood pressure: the CARDIA Study of young black and white adults. Am J Pub Health 1996;86(10):1370-8.

23. Brondolo E, Rieppi R, Kelly KP, Gerin W. Perceived racism and blood pressure: a review of the literature and conceptual and methodological critique. Ann Behav Med 2003;25(1):55-65.

24. Karlsen S, Nazroo JY. Relation between racial discrimination, social class, and health among ethnic minority groups. Am J Pub Health 2002;92(4):624-31.

25. Schulz A, Israel B, Williams D, Parker E, Becker A, James S. Social inequalities, stressors and self reported health status among African American and white women in the Detroit metropolitan area. Soc Sci Med 2000;51(11):1639-53.

26. Stuber J, Galea S, Ahern J, Blaney S, Fuller C. The association between multiple domains of discrimination and self- assessed health: a multilevel analysis of Latinos and blacks in four low- income New York City neighborhoods. Health Serv Res 2003;38(6p2):1735-60.

27. Finch BK, Hummer RA, Kol B, Vega WA. The role of discrimination and acculturative stress in the physical health of Mexican-origin adults. Hisp J Behav Sci 2001;23(4):399-429.

28. Gee GC, Chen J, Spencer MS, See S, Kuester OA, Tran D, Takeuchi D. Social support as a buffer for perceived unfair treatment among Filipino Americans: differences between San Francisco and Honolulu. Am J Pub Health 2006;96(4):677-84.

29. Krieger N, Smith K, Naishadham D, Hartman C, Barbeau EM. Experiences of discrimination: validity and reliability of a self-report measure for population health research on racism and health. Soc Sci Med 2005;61(7):1576-96.

30. Grant JM, Mottet LA, Tanis JJ, Min D. Transgender Discrimination Survey. Washington, DC. 2011.

31. Mustanski BS, Garofalo R, Emerson EM. Mental health disorders, psychological distress, and suicidality in a diverse sample of lesbian, gay, bisexual, and transgender youths. Am J Pub Health 2010;100(12):2426-32. 
32. Kessler RC, Berglund P, Borges G, Nock M, Wang PS. Trends in suicide ideation, plans, gestures, and attempts in the United States, 1990-1992 to 2001-2003. Jama. 2005 May 25;293(20):2487-95.

33. Kristen Clements-Nolle PhD MP, Rani Marx PhD MP, Katz M. Attempted Suicide Among Transgender Persons. Journal of Homosexuality.

34. Nemoto T, Bödeker B, Iwamoto M. Social support, exposure to violence and transphobia, and correlates of depression among male-to-female transgender women with a history of sex work. American journal of public health. 2011 Oct;101(10):1980-8.

35. Nuttbrock L, Rosenblum A, Blumenstein R. Transgender identity affirmation and mental health. Int J Transgenderism 2002;6(4):1-2.

36. Hepp U, Kraemer B, Schnyder U, Miller N, Delsignore A. Psychiatric comorbidity in gender identity disorder. J Psychosom Res 2005;58(3):259-61.

37. Budge SL, Katz-Wise SL, Tebbe EN, Howard KA, Schneider CL, Rodriguez A. Transgender emotional and coping processes: Facilitative and avoidant coping throughout gender transitioning. The Couns Psychol 2013;41(4):601-47.

38. Grossman AH, D'augelli AR. Transgender youth: Invisible and vulnerable. J Homosexuality 2006;51(1):11128.

39. Pascoe EA, Smart Richman L. Perceived discrimination and health: a meta-analytic review. Psychol Bull 2009;135(4):531-8.

40. Harris R, Tobias M, Jeffreys M, Waldegrave K, Karlsen S, Nazroo J. Racism and health: The relationship between experience of racial discrimination and health in New Zealand. Soc Sci Med 2006;63(6):1428-41.

41. Lindström B. The Essence of Existence: On the Quality of Life of Children in the Nordic Countries-Theory and Practice in Public Health. Nordic School of Public Health; 1994.

42. Başar K, Öz G, Karakaya J. Perceived discrimination, social support, and quality of life in gender dysphoria. J Sex Med 2016;13(7):1133-41.

43. Diener ED, Emmons RA, Larsen RJ, Griffin S. The satisfaction with life scale. J Personal Assess 1985;49(1):71-5.

44. Pandey, Manoj Kumar. Survivors of Domestic Violence: A Journey of Disempowerment to Empowerment. In Dr. Ashish Kumar Gupta Edited Book on "The Third Gender- Stain and Pain”, Vishwabharati Research Centre Lathur Maharashtra, New Delhi (In Press). 2018.

45. Supreme Court of India. Decision on Third Gender Status to Transgenders." Retrieved from http://www.lawyerscollective.org/wpcontent/uploads/2014/04/Transgender-judgment.pdf. 2014

46. World Health Organization. Promoting mental health: Concepts, emerging evidence, practice: Summary report.

$* * * * * * * * * * * * * * * * * * * * * * * * * * * * * * * * * * * *$

Acknowledgements - All the participants of this study who supported me in this project.

Conflict of Interest - Nil

Funding - Nil 